\title{
Acquired Autoimmune Hemophilia Following SARS-CoV-2 Vaccines: Dual-Drug Effects on Blood Coagulation and the Scylla and Charybdis Phenomenon
}

\author{
Job Harenberg ${ }^{1,2}$ Marina Marchetti ${ }^{3} \quad$ Anna Falanga 3,40
}

${ }^{1}$ Ruprecht-Kalrs University Heidelberg, Heidelberg, Germany
2 Department of Medicine, DOASENSE GmbH, Heidelberg, Germany
${ }^{3}$ Division of Immunohematology and Transfusion Medicine, Hospital
Papa Giovanni XXIII, Bergamo, Italy
${ }^{4}$ School of Medicine and Surgery, University of Milan Bicocca, Milan, Italy

Thromb Haemost 2021;121:1555-1557.
Address for correspondence Job Harenberg, MD, Department of Medicine, DOASENSE GmbH, Waldhoferstrasse 102, 69123 Heidelberg, Germany (e-mail: j.harenberg@doasense.de).

previously to heparin. ${ }^{8,9}$ This syndrome, named vaccineinduced immune thrombotic thrombocytopenia (VITT), is associated with high fatality rate. ${ }^{10}$ The U.S. Vaccine Adverse Event Reporting System and the U.K. Medicines and Healthcare products Regulatory Agency established coronavirus reporting systems and have made clear that the benefits of SARS-CoV-2 vaccination far outweigh the risk of VITT. ${ }^{11}$

\section{Other Immunological Reactions to SARS-CoV-2 Vaccines}

In addition to immunothrombosis, other immunological reactions to SARS-CoV-2 vaccines have been as well described. It is suggested that autoantibodies against the spike protein S1 of SARS-CoV-2 may be responsible for these complications as reported for immune thrombocytopenia, ${ }^{12}$ vasculitis, ${ }^{13}$ Schönlein-Henoch pupura, ${ }^{14}$ autoimmune hepatitis, ${ }^{15}$ and Guillain-Barré syndrome. ${ }^{16}$ Additional case reports may increase the number of so far unknown immunological reactions to the available vaccines. Of note, some of the reactions were already described in the efficacy and safety studies of SARS-CoV-2 vaccines. ${ }^{17}$

\section{Autoantibodies to Clotting Factor VIII after SARS-CoV-2 Vaccines}

In mid-2021, the first cases of bleeding complications were reported 15 to 19 days (or later) after vaccination with adenoviral vector vaccine ChAdOx $1 .{ }^{18}$ Farley et al report on a case of acquired hemophilia with a large hematoma of his left posterior leg extending from his buttock to below his received

September 21, 2021

accepted

September 28, 2021

published online

September 30, 2021 (c) 2021. Thieme. All rights reserved. Georg Thieme Verlag KG,

Rüdigerstraße 14,

70469 Stuttgart, Germany
DOI https://doi.org/ 10.1055/a-1658-4852. ISSN 0340-6245. 
left knee, 19 days after the second dose of BNT162b2 PfizerBioNTech vaccine. Laboratory values revealed a two- to threefold prolongation of the activated partial thromboplastin time (aPTT), decrease of hemoglobin to $10 \mathrm{~g} / \mathrm{dL}$, factor VIII activity $<1 \%$, and 110 Bethesda Units/mL of factor VIII inhibitor. Platelet count, creatinine, and other laboratory parameters were in the normal range. The patient had no personal and family history of hemorrhagic diseases. The patient recovered without sequelae after adequate treatment. ${ }^{19}$

Other case reports also described the development of acquired hemophilia after SARS-CoV-2 vaccination. ${ }^{20-22}$ These reports have as common the development of hemophilia with major bleeding following vaccination with one of the approved SARS-CoV-2 vaccines. All patients described so far presented with prolonged aPTT values, undetectable factor VIII levels, elevated factor VIII inhibitor concentrations, decreased platelet count, and reduced hemoglobin levels. After adequate treatment measures, they all recovered without sequelae and normalized coagulation values within a couple of weeks. One of these cases presented with negative polymerase chain reaction SARS-CoV-2 test and positive SARS-CoV-2 IgG antibodies, thus excluding with high probability that acquired hemophilia was an immunological reaction to virus. ${ }^{22}$ Interest- ingly, the development of a factor VIIIIc inhibitor was already described in a patient with lichenoid dermatosis who had been vaccinated with BCG (Bacillus CalmetteGuérin) and a pool of various strains of live-attenuated corynebacteria and recovered without sequels after specific treatments. ${ }^{23}$

\section{Anticoagulation and SARS-CoV-2 Vaccines}

Thrombosis and hemorrhage may be a result of thromboinflammation due to viral infections, and the role of anticoagulation is important to consider. ${ }^{24}$ Administration of anticoagulants is of huge importance for thrombotic disease prevention in COVID-19 patients, and heparins (unfractionated or low-molecular-weight heparins) are the currently recommended agents for hospitalized COVID-19 patients..$^{25,26}$ Nevertheless, excessive doses and/or an accumulative effect of heparins may favor bleeding, mainly in the hemorrhagic phase of the infectious disease when multiorgan failure also occurs. Therefore, from patients' point of view, anticoagulants and SARS-CoV-2 vaccines share their capacity to induce thrombosis as well as bleeding. Thus, clinicians are subjected to choosing between Scylla and Charybdis when they treat patients not only with anticoagulants but also with SARSCoV-2 vaccines (-Fig. $\mathbf{1}$ ).

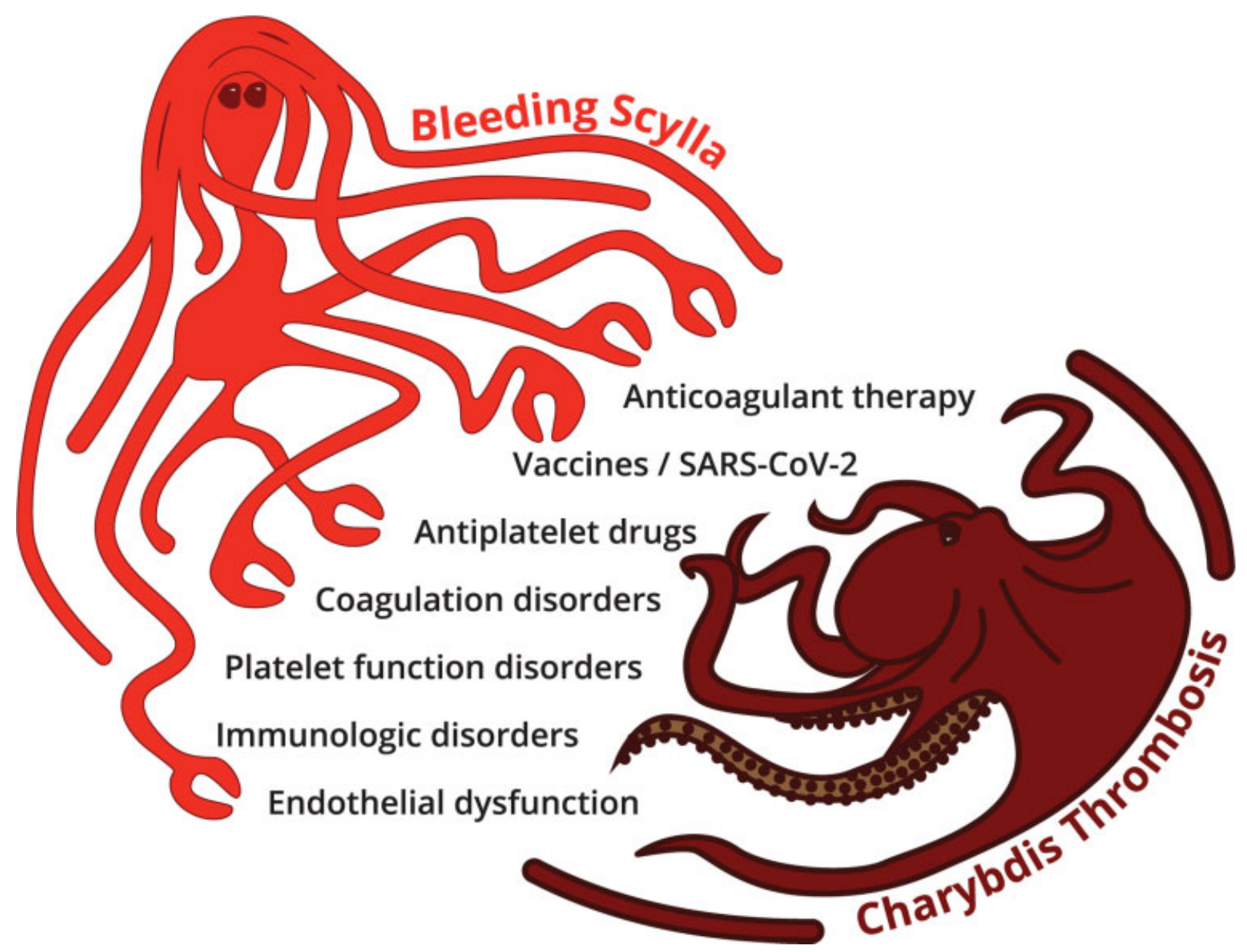

Fig. 1 Scylla and Charybdis phenomenon in hemostasis: similarities between anticoagulants, SARS-CoV-2 vaccines, and selected other pathways (Copyright.com.de; deposit number: DEP637698427981306749). 


\section{What the Future May Offer}

Several aspects will guide in future due to immunological reactions to SARS-CoV-2 vaccines:

- Screening of patients for clinical symptoms of thrombosis and bleeding following vaccination may be regarded as an option. $^{27}$

- Autoantibodies may be detected to other coagulation factors, proteins on platelet, and endothelium surface capable to induce bleeding and/or thrombotic events.

- Pan-sarbecovirus vaccines could seek to improve responses to this epitope by unmasking this and other cryptic broadly neutralizing epitopes ${ }^{28}$ aiming to reduce immunologic blood coagulation effects.

- Careful analysis of coincidence and causality requires attention when reporting on acquired coagulation inhibitors regarding severity, treatments, duration, and statistical risk. ${ }^{29}$

- Careful documentation of case reports on immunological reaction to SARS-CoV-2 vaccines and of respective reactions from clinical studies in national and international registries.

\section{Conflict of Interest}

None declared.

\section{References}

1 Bikdeli B, Madhavan MV, Gupta A, et al; Global COVID-19 Thrombosis Collaborative Group. Pharmacological agents targeting thromboinflammation in COVID-19: review and implications for future research. Thromb Haemost 2020;120(07):1004-1024

2 Boscolo A, Spiezia L, Correale C, et al. Different hypercoagulable profiles in patients with COVID-19 admitted to the internal medicine ward and the intensive care unit. Thromb Haemost 2020;120(10):1474-1477

3 Polack FP, Thomas SJ, Kitchin N, et al; C4591001 Clinical Trial Group. Safety and efficacy of the BNT162b2 mRNA Covid-19 vaccine. N Engl J Med 2020;383(27):2603-2615

4 Voysey M, Clemens SAC, Madhi SA, et al; Oxford COVID Vaccine Trial Group. Safety and efficacy of the ChAdOx1 nCoV-19 vaccine (AZD1222) against SARS-CoV-2: an interim analysis of four randomised controlled trials in Brazil, South Africa, and the UK. Lancet 2021;397(10269):99-111

5 Shazley O, Alshazley M. A COVID-positive 52-year-old man presented with venous thromboembolism and disseminated intravascular coagulation following Johnson \& Johnson vaccination: a case-study. Cureus 2021;13(07):e16383

6 Marchandot B, Trimaille A, Curtiaud A, et al. Staging severity of COVID-19 according to hemostatic abnormalities (CAHA Score). Thromb Haemost 2020;120(12):1716-1719

7 Khandelwal S, Arepally GM. Immune pathogenesis of heparininduced thrombocytopenia. Thromb Haemost 2016;116(05): 792-798

8 Greinacher A, Thiele T, Warkentin TE, Weisser K, Kyrle PA, Eichinger S. Thrombotic thrombocytopenia after ChAdOx1 nCov-19 vaccination. N Engl J Med 2021;384(22):2092-2101

9 Schultz NH, Sørvoll IH, Michelsen AE, et al. Thrombosis and thrombocytopenia after ChAdOx1 $\mathrm{nCoV}-19$ vaccination. $\mathrm{N}$ Engl J Med 2021;384(22):2124-2130

10 Vayne C, Nguyen TH, Rollin J, et al. Characterization of new monoclonal PF4-specific antibodies as useful tools for studies on typical and autoimmune heparin-induced thrombocytopenia. Thromb Haemost 2021;121(03):322-331

11 Khin NA, Grandinetti C, Dixey H, et al. Tackling challenging data integrity topics in 2020: update on good clinical practice perspectives from the US FDA and MHRA UK. Clin Pharmacol Ther 2021. Doi: $10.1002 /$ cpt.2386

12 Lee EJ, Cines DB, Gernsheimer T, et al. Thrombocytopenia following Pfizer and Moderna SARS-CoV-2 vaccination. Am J Hematol 2021;96(05):534-537

13 Shakoor MT, Birkenbach MP, Lynch M. ANCA-associated vasculitis following Pfizer-BioNTech COVID-19 vaccine. Am J Kidney Dis 2021;78(04):611-613

14 Hines AM, Murphy N, Mullin C, Barillas J, Barrientos JC. HenochSchönlein purpura presenting post COVID-19 vaccination. Vaccine 2021;39(33):4571-4572

15 Vuille-Lessard É, Montani M, Bosch J, Semmo N. Autoimmune hepatitis triggered by SARS-CoV-2 vaccination. J Autoimmun 2021;123:102710

16 Filosto M, Cotti Piccinelli S, Gazzina S, et al. Guillain-Barré syndrome and COVID-19: an observational multicentre study from two Italian hotspot regions. J Neurol Neurosurg Psychiatry 2021;92(07):751-756

17 Hines A, Shen JG, Olazagasti C, Shams S. Immune thrombocytopenic purpura and acute liver injury after COVID-19 vaccine. BMJ Case Rep 2021;14(07):e242678

18 Franchini M, Glingani C, De Donno G, et al. The first case of acquired hemophilia A associated with SARS-CoV-2 infection. Am J Hematol 2020;95(08):E197-E198

19 Farley S, Ousley R, Van Wagoner N, Bril F. Autoimmunity after coronavirus disease 2019 (COVID-19) vaccine: a case of acquired hemophilia A. Thromb Haemost 2021;121(12):1674-1676

20 Radwi M, Farsi S. A case report of acquired hemophilia following COVID-19 vaccine. J Thromb Haemost 2021;19(06):1515-1518

21 Portuguese AJ, Sunga C, Kruse-Jarres R, Gernsheimer T, Abkowitz J. Autoimmune- and complement-mediated hematologic condition recrudescence following SARS-CoV-2 vaccination. Blood Adv 2021;5(13):2794-2798

22 Wang KY, Shah P, Roarke DT, Shakil SA. Severe acquired haemophilia associated with asymptomatic SARS-CoV-2 infection. BMJ Case Rep 2021;14(07):e242884

23 Ferri GM, Vaccaro F, Caccavo D, Imperato G, Bonomo L. Development of factor VIII:C inhibitors following vaccination. Acta Haematol 1996;96(02):110-111

24 Gencer S, Lacy M, Atzler D, van der Vorst EPC, Döring Y, Weber C. Immunoinflammatory, thrombohaemostatic, and cardiovascular mechanisms in COVID-19. Thromb Haemost 2020;120(12): 1629-1641

25 Patell R, Chiasakul T, Bauer E, Zwicker JI. Pharmacologic thromboprophylaxis and thrombosis in hospitalized patients with COVID-19: a pooled analysis. Thromb Haemost 2021;121(01): 76-85

26 Bikdeli B, Talasaz AH, Rashidi F, et al. Intermediate-dose versus standard-dose prophylactic anticoagulation in patients with COVID-19 admitted to the intensive care unit: 90-day results from the INSPIRATION randomized trial. Thromb Haemost 2021. Doi: $10.1055 / \mathrm{a}-1485-2372$

27 Elalamy I, Gerotziafas G, Alamowitch S, et al; Scientific Reviewer Committee. SARS-CoV-2 vaccine and thrombosis: an expert consensus on vaccine-induced immune thrombotic thrombocytopenia. Thromb Haemost 2021;121(08):982-991

28 Starr TN, Czudnochowski N, Liu Z, et al. SARS-CoV-2 RBD antibodies that maximize breadth and resistance to escape. Nature 2021;597(7874):97-102

29 Cittone MG, Battegay R, Condoluci A, et al. The statistical risk of diagnosing coincidental acquired hemophilia A following anti-SARSCoV-2 vaccination. J Thromb Haemost 2021;19(09):2360-2362 